University of Wollongong

Research Online

Faculty of Engineering and Information

Faculty of Engineering and Information

Sciences - Papers: Part A

Sciences

$1-1-2012$

\title{
Flicker propagation analysis in distribution networks with embedded generation
}

D Perera

University of Wollongong, bmdp065@uowmail.edu.au

L Meegahapola

University of Wollongong, lasantha.meegahapola@rmit.edu.au

S Perera

University of Wollongong, sarath@uow.edu.au

P Ciufo

University of Wollongong, ciufo@uow.edu.au

Follow this and additional works at: https://ro.uow.edu.au/eispapers

Part of the Engineering Commons, and the Science and Technology Studies Commons

Research Online is the open access institutional repository for the University of Wollongong. For further information contact the UOW Library: research-pubs@uow.edu.au 


\title{
Flicker propagation analysis in distribution networks with embedded generation
}

\author{
Abstract \\ Embedded generators such as wind generators can produce observable voltage fluctuations during \\ variable wind conditions hence flicker. The flicker produced by such intermittent and fluctuating \\ generating sources can propagate to other parts of the distribution network while creating power quality \\ issues in distribution feeders. This study presents a flicker emission analysis for a doubly-fed induction \\ generator (DFIG) based wind farm and investigate the pertinent factors which influence flicker \\ propagation and attenuation in distribution feeders. Study has shown that voltage fluctuations are \\ significantly influenced by the attenuation characteristics of various load types (i.e. constant power, \\ impedance and current loads) connected to distribution network. Moreover, operating power factor of the \\ wind farm has significantly influenced on flicker produced at the point of common coupling (PCC) of the \\ wind farm and flicker propagation along the feeder. The outcome of the research is beneficial in \\ understanding the flicker propagation in the distribution network in the presence of embedded generation.

\section{Keywords} \\ generation, networks, embedded, distribution, flicker, analysis, propagation \\ Disciplines \\ Engineering | Science and Technology Studies

\section{Publication Details} \\ D. Perera, L. Meegahapola, S. Perera \& P. Ciufo, "Flicker propagation analysis in distribution networks with \\ embedded generation," in IEEE International Conference on Power System Technology (POWERCON), \\ 2012, pp. 1-6.
}




\title{
Flicker Propagation Analysis in Distribution Networks with Embedded Generation
}

\author{
D. Perera, Student Member, IEEE, L. Meegahapola, Member, IEEE, S. Perera, Member, IEEE and \\ P. Ciufo, Senior Member, IEEE
}

\begin{abstract}
Embedded generators such as wind generators can produce observable voltage fluctuations during variable wind conditions hence flicker. The flicker produced by such intermittent and fluctuating generating sources can propagate to other parts of the distribution network while creating power quality issues in distribution feeders. This study presents a flicker emission analysis for a doubly-fed induction generator (DFIG) based wind farm and investigate the pertinent factors which influence flicker propagation and attenuation in distribution feeders. Study has shown that voltage fluctuations are significantly influenced by the attenuation characteristics of various load types (i.e. constant power, impedance and current loads) connected to distribution network. Moreover, operating power factor of the wind farm has significantly influenced on flicker produced at the point of common coupling (PCC) of the wind farm and flicker propagation along the feeder. The outcome of the research is beneficial in understanding the flicker propagation in the distribution network in the presence of embedded generation.
\end{abstract}

Index Terms-Doubly-fed induction generator (DFIG), flicker attenuation, flicker propagation, load type, power factor control, wind generation.

\section{INTRODUCTION}

G LOBAL drive towards operating a clean and sustainable electrical power system has resulted in large penetrations of renewable energy generators (REGs) in distribution networks. However, integration of REGs into distribution networks has given rise to technical challenges such as voltage instability and power quality. The key power quality challenges include steady-state voltage increase, harmonic and interharmonic voltages, voltage unbalance, and flicker.

Wind energy is a cost effective power generation option which has a low impact on environment. At the end of 2011, the worldwide installed wind capacity was $238 \mathrm{GW}$, and during the year 2011 a further $41 \mathrm{GW}$ of wind capacity was added to power networks, indicating a $20.81 \%$ increase in wind power capacity [1]. At present most of the wind energy generation systems are connected to distribution networks [2]. Therefore, when wind power penetration level increases, that may deteriorate the quality of electricity supply in the distribution network. One of the key power quality issues with respect to wind power generation is flicker [3].

Many researchers have investigated flicker emission from wind generators [4] [5] [6]. Variable and intermittent nature

D. Perera, L. Meegahapola, S. Perera and P. Ciufo are with the School of Electrical, Computer and Telecommunications Engineering, University of Wollongong, and are Members of the Endeavour Energy Power Quality and Reliability Centre, NSW 2522, Australia (email: lasantha@uow.edu.au). of wind, aerodynamic effects such as tower shadow effect, and yaw error, are the pertinent factors for flicker emission from wind generators [7]. Studies conducted on flicker emission from wind farms have demonstrated instances where flicker emission exceeding the regulatory limits [8]. However, power electronics based wind generators such as doubly-fed induction generators (DFIGs) have significantly lower flicker emission level in comparison to the fixed-speed wind generators (FSIGs), due to their robust active and reactive power control capability [6]. However, flicker mitigation capabilities of the DFIG are limited due to reactive power capability characteristics of the DFIG [9].

Many flicker studies have been conducted considering the unity power factor operation of the DFIG [6]. However, modern grid-codes require wind farms to operate at leading and lagging power factors in order to provide reactive power support to the network and manage the voltage profile of distribution feeders within stipulated grid-code limits [10]. Therefore, flicker emission and propagation studies with different operating power factors are required to characterise the flicker emission from wind generators.

Furthermore, flicker caused by active and reactive power fluctuations can propagate to upstream and downstream network with some attenuation. The current technical literature has extensively investigated the flicker transfer and propagation [11] [12]. In [11] authors have advocated that the flicker propagation to upstream network depends on the fault level at each location. Similarly, flicker propagation to downstream network is influenced by load composition [13]. However, these studies are based on distribution network where active and reactive power flow is uni-directional. With the increasing penetration level of embedded generators such as wind generation, active and reactive power flow become bi-directional. Therefore, flicker propagation must be investigated to characterise the flicker levels under bi-directional power flows in distribution feeders. In addition, distribution system loads may also influence on flicker propagation and attenuation [14]. Flicker attenuation from induction motors was well researched in technical literature [15] [16]. However, flicker propagation and attenuation due to other load types such as constant power and constant current loads have not been adequately researched.

The objective of the current research is to investigate the flicker propagation and attenuation in distribution networks with wind generation. In addition, influence of different load types (i.e. constant impedance, constant current, constant power and induction motor loads) on flicker propagation and 


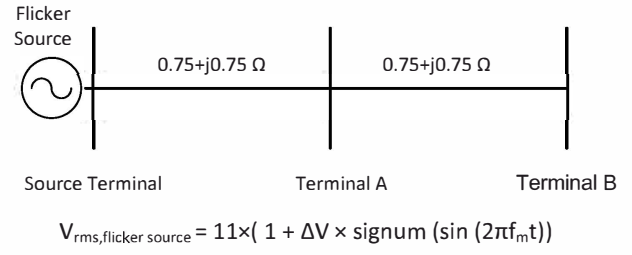

Fig. 1. $11 \mathrm{kV}$ radial network model.

attenuation will also be investigated. A wind farm consisted of DFIG wind generators has been modeled in DIgSILENT Power Factory [17] [18] in order to investigate flicker emission from wind generation.

This paper is structured as follows: Section II investigates the impact of different load types (e.g. constant power, constant current, constant impedance) on flicker propagation. The influence of operating power factor of a wind farm on flicker emission is presented in Section III. Flicker propagation in distribution network with wind generation is investigated in Section IV. Section V presents a case study on flicker propagation in a distribution feeder consisted of different load types and a wind farm. Finally, the conclusions and the future studies are presented in Section VI.

\section{INFLUENCE OF LOAD TYPE ON FLICKER PROPAGATION}

In order to investigate the effects of constant impedance (Z), constant current (I), and constant power (P) load types on flicker propagation, a $11 \mathrm{kV}$ network with a flicker source is modeled in DIgSILENT Power Factory (see Fig. 1). The flicker source is a rectangularly modulated $11 \mathrm{kV}$ voltage source with a modulation frequency $\left(f_{m}\right)$ of $10 \mathrm{~Hz}$ and modulation depth $(\Delta V)$ of $0.1 \%$. Fig. 2-(a) and (b) illustrate the flicker transfer coefficients $\left(T_{P_{s t}}\right)$ for $\mathrm{Z}, \mathrm{I}$ and $\mathrm{P}$ loads with capacities from 1 MVA to 5 MVA with 0.9 power factor, are connected to the terminal A and terminal B respectively. Flicker transfer coefficient $\left(T_{P_{s t}}\right)$ is given by;

$$
T_{P_{s t}}=\frac{P_{\text {st }, \text { load }}}{\mathrm{P}_{\text {st }, \text { source }}}
$$

where, $\mathrm{P}_{\text {st,load }}$ and $\mathrm{P}_{\text {st,load }}$ are the short-term flicker severity at the source terminal and load terminal.

Figs. 2-(a) and -(b) illustrate that presence of constant power and constant current loads has exacerbated the flicker levels at the load terminal. Furthermore, the flicker transfer coefficient increases with the increase in load MVA capacity and impedance between the flicker source and the load. For instance, flicker transfer coefficient has increased from 1.02 to 1.095 when the MVA capacity of the constant power load connected to terminal A is increased from 1 MVA to 5 MVA. Similarly, flicker transfer coefficient has increased from 1.095 to 1.225 if 5 MVA constant power load with 5 MVA capacity is moved from terminal A to terminal B. Similar observations can be made with respect to constant current loads. However, the constant impedance load has less impact on flicker level at the load busbar.

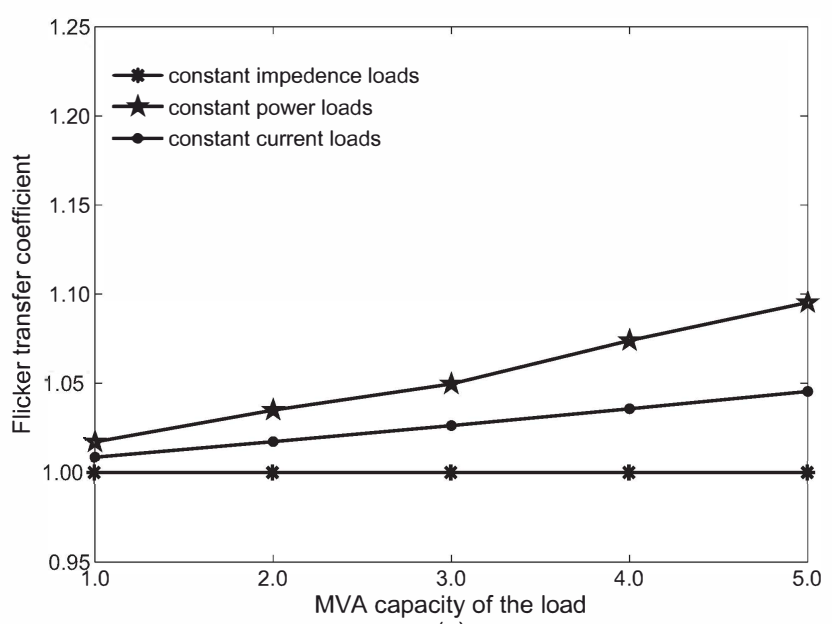

(a)

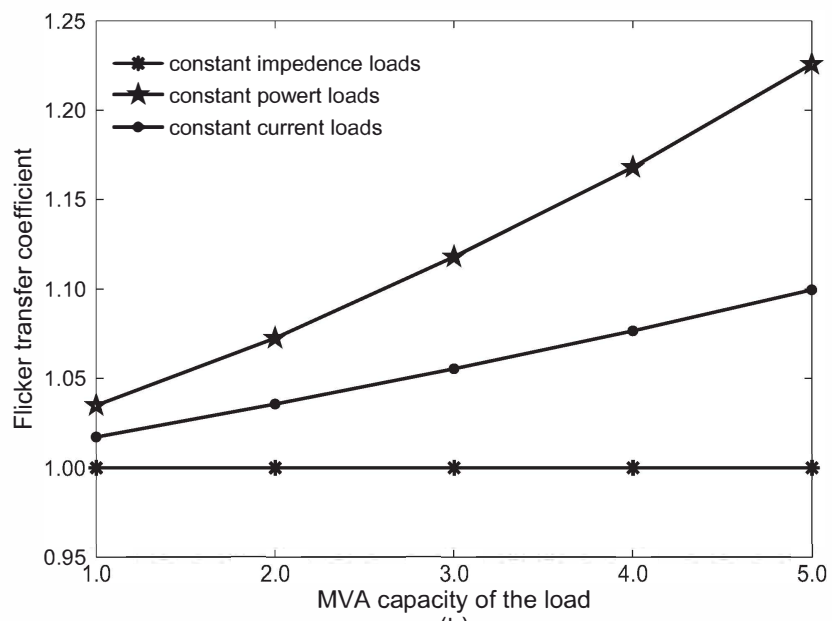

(b)

Fig. 2. Flicker transfer coefficient if the load is connected to (a) terminal A; (b) terminal B.

In order to explain the behaviour of $\mathrm{Z}, \mathrm{I}$ and $\mathrm{P}$ loads on flicker propagation, flicker transfer coefficient in (1) can be modified as;

$$
T_{P_{s t}} \approx \frac{\frac{\Delta V_{\text {load }}}{V_{\text {load }}}}{\frac{\Delta V_{\text {source }}}{V_{\text {source }}}}=\frac{\Delta V_{\text {load }}}{\Delta V_{\text {source }}} \cdot \frac{V_{\text {source }}}{V_{\text {load }}}
$$

where $\Delta V_{\text {source }}, \Delta V_{\text {load }}, V_{\text {source }}$ and $V_{\text {load }}$ are voltage change at the source terminal, voltage change at the load terminal, steady-state voltage at the source terminal and steadystate voltage at the load terminal respectively. The steadystate voltage at the load terminal depends on the type of the load connected to the load terminal. However, the ratio $V_{\text {source }} / V_{\text {load }}$ is greater than unity for most distribution systems loads irrespective of its load type (i.e. Z, I or P).

When a constant current load is connected, the voltage change at the load terminal is equal to voltage change at the source terminal, since the current flow in the network is constant. However, the relative voltage change (i.e. $\Delta V_{\text {load }} / V_{\text {load }}$ ) will be greater at the load busbar compared to the relative voltage change (i.e. $\Delta V_{\text {source }} / V_{\text {source }}$ ) at the source busbar (since $V_{\text {source }}$ is greater than $V_{\text {load }}$ ). Accordingly, flicker levels at the load busbar will be greater than flicker levels at the source busbar. In the presence of constant power loads, voltage 
change at the load terminal aggravate, in order to maintain the active and reactive power constant (i.e. $\Delta V_{\text {load }} / \Delta V_{\text {source }}>1$ ). Consequently, the flicker level at the load terminal is high in comparison to a constant current loads. In contrast the voltage change occurring at the load terminal will attenuate and will be less than the voltage change at the source terminal, if a constant impedance load is connected (i.e. $\Delta V_{\text {load }} / \Delta V_{\text {source }}<1$ ). However, since $V_{\text {source }} / V_{\text {load }}>1, T_{P_{s t}}$ will remain constant at unity. In addition, $\Delta V_{\text {source }}, \Delta V_{\text {load }}, V_{\text {source }}$ and $V_{\text {load }}$ are dependent on line impedance and line $\mathrm{X} / \mathrm{R}$ ratio. Consequently, the flicker transfer coefficient will also be dependent on the impedance between the source and the load and distribution line $\mathrm{X} / \mathrm{R}$ ratio.

\section{FLICKER EMISSION OF WIND FARMS UNDER DIFFERENT OPERATING POWER FACTORS}

The impact of the operating power factor of a wind farm on flicker emission is analysed in this section. A $19.5 \mathrm{MW}$ $(1.5 \mathrm{MW} \times 13)$ DFIG wind farm connected to a $33 \mathrm{kV}$ distribution line was modeled in DIGSILENT Power Factory [17]. The schematic of the modeled MV network is given in Fig. 3. The network parameters and characteristics of the wind profile for the study case is given in Table I. The operating power factor of the wind farm was varied from leading power factor 0.85 to lagging power factor 0.85 . Short-term flicker severity at the point of common coupling (PCC) of the wind farm under variable wind conditions [19] was recorded in accordance with IEC 61000-4-15 [20]. Flicker emission from the wind farm as a function of operating power factor is given in Fig. 4.

TABLE I

NETWORK PARAMETERS AND CHARACTERISTICS OF THE WIND PROFILE FOR THE STUDY CASE

\begin{tabular}{lc}
\hline Mean wind speed & $7.5 \mathrm{~ms}^{-1}$ \\
Turbulence Intensity & $10 \%$ \\
Line impedance & $0.3+\mathrm{j} 0.3 \Omega / \mathrm{km}$ \\
Short-circuit level at the HV busbar & $500 \mathrm{MVA}$ \\
\hline
\end{tabular}

Fig. 4 illustrates that when the wind farm is operating at leading power factors, flicker emission has significantly increased when compared to unity power factor case. For example, short-term flicker severity which is 0.19 under unity power factor operation has increased to 0.42 when operating under 0.85 leading power factor. $\mathrm{P}_{\text {st }}$ has further decreased to 0.14 if the operating power factor is changed to 0.95 lagging power factor. However, $\mathrm{P}_{\text {st }}$ will then gradually increase if the operating power factor is further changed to 0.90 and 0.85 lagging power factors.

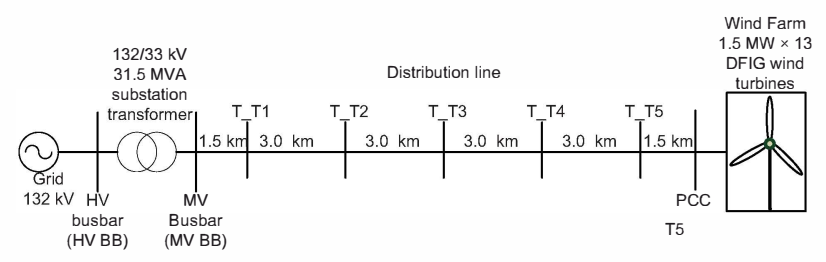

Fig. 3. Single line diagram of the MV network
Short-term flicker severity and voltage change $(\Delta V)$ due to variable active and reactive power are correlated. Hence, $\Delta V$ can be utilised to explain the behavior of $\mathrm{P}_{\text {st }}$ under various power factor operating conditions. $\Delta V$ from a grid connected generator can be approximated by,

$$
\Delta V \approx \frac{R \cdot \Delta P+X \cdot \Delta Q}{V_{g}}
$$

where $\Delta V, \Delta P, \Delta Q$ and $V_{g}$ denote change of voltage, change in active power, change in reactive power and generator voltage respectively. $R$ and $X$ denote the effective resistance and reactance seen at the PCC of the wind farm which includes, impedance of the distribution line, impedance of the $\mathrm{HV} / \mathrm{MV}$ transformer and $\mathrm{HV}$ grid impedance.

When the wind farm is operating at a leading power factor active and reactive power flow from wind farm to the grid. Therefore, with decreasing power factor ( i.e. increasing reactive power) voltage change $(\Delta V)$ will become severe, since $R \cdot \Delta P$ and $X \cdot \Delta Q$ components add together. In contrast, when operating at lagging power factor, reactive power flow is in the opposite direction to active power flow. Thus, $\Delta V$ will reduces leading to a low $\mathrm{P}_{\mathrm{st}}$ value. However, if the operating power factor is further reduced, $X \cdot \Delta Q$ term in (3) will become dominant, and $\Delta V$ will start increasing. Consequently $\mathrm{P}_{\mathrm{st}}$ value will increase.

Moreover, mean wind speed, wind turbulence intensity, short-circuit ratio at the point of grid connection of a wind farm and grid impedance angle (i.e. distribution line $X / R$ ratio) have been identified as parameters which influence on flicker emission [6]. Thus, the impact of strong shortcircuit capacity at the point of grid connection and X/R ratio of the distribution line, on flicker emission was investigated under various operating power factors. The short-term flicker severity for different power factors as a function of shortcircuit capacity at the $\mathrm{HV}$ buabar of the substation, and as function of distribution line $\mathrm{X} / \mathrm{R}$ are given in Fig. 5 .

Fig. 5-(a) demonstrates that if a wind farm is connected to a strong $\mathrm{HV}$ grid, flicker level at the PCC is marginally lower, compared to a wind farm connected to a weak HV grid. In

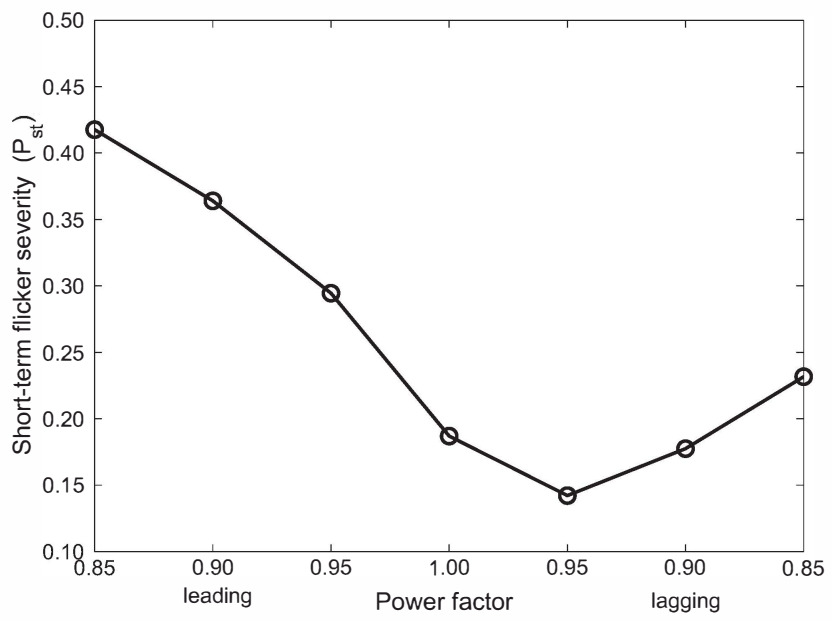

Fig. 4. Variation of short-term flicker severity under different operating power factors 


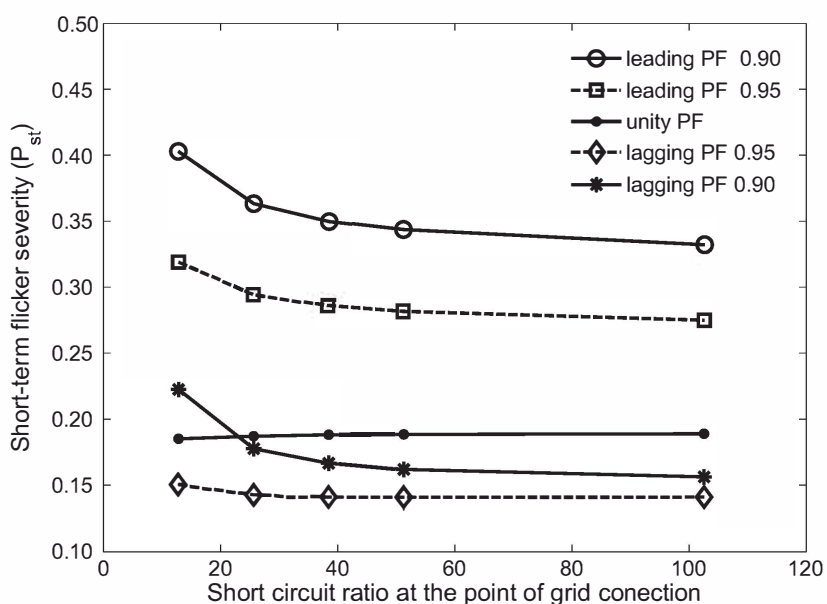

(a)

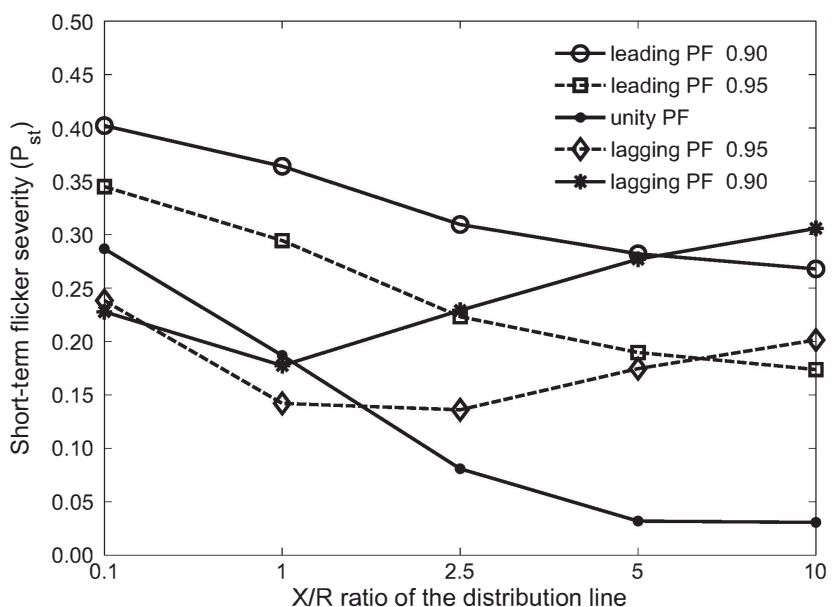

(b)

Fig. 5. Short-term flicker severity (a) as a function of short-circuit ratio at the point of grid connection; (b) as a function of $\mathrm{X} / \mathrm{R}$ ratio of the distribution line, for different power factors

a distribution network, total resistance and reactance at the PCC of the wind farm are mainly dominated by resistance and reactance of the distribution line and the HV/MV transformer. Therefore, short-circuit capacity of the HV busbar will not substantially impact on flicker emission from the wind farm. Moreover, since HV grid is mainly inductive, higher shortcircuit capacity will have a negligible effect on flicker emission at unity power factor. Therefore, short-term flicker severity will remain approximately constant with increasing short-circuit ratio as seen in Fig. 5-(a).

Fig. 5-(b) illustrates that $\mathrm{X} / \mathrm{R}$ ratio of distribution line affects flicker emission and depends on the operating power factor of the wind farm. Flicker emission from the wind farm reduces with increasing $\mathrm{X} / \mathrm{R}$ ratio when operating at unity power factor, due to the reduction of effective resistance at the PCC [6]. Likewise, flicker levels will reduce under leading power factor operation, with increasing $\mathrm{X} / \mathrm{R}$ ratio. However, the reduction is not significant compared to the unity power factor operation. This is due to the influence of $X \cdot \Delta Q$ component, in (3), which increases with effective reactance $(X)$. In contrast, if the wind farm is operating at a lagging power factor $P_{s t}$ is observed to reach a minimum value and then keep on increasing with
$\mathrm{X} / \mathrm{R}$ ratio. For instance, the wind farm when operating at a 0.90 lagging power factor will have a $P_{\text {st }}$ value of 0.23 at the $\mathrm{PCC}$ if it is connected to through a line with $\mathrm{X} / \mathrm{R}$ ratio of 0.1 . However, if the wind farm is connected through a line with $\mathrm{X} / \mathrm{R}$ ratio of 1 , it will produce flicker level of 0.17 . If the same wind farm is connected through a line with $\mathrm{X} / \mathrm{R}$ ratio of 10 , it will give arise to a flicker level of Pst $=0.3059$. This is because when $\mathrm{X} / \mathrm{R}$ ratio is increased to less than one voltage fluctuation due to reactive power component cancels a part of voltage fluctuation due to active power component. However, if $\mathrm{X} / \mathrm{R}$ ratio is further increased voltage fluctuation due to reactive power component becomes dominant, therefore, according to (3) voltage fluctuation will increase.

Similar study was conducted to assess the impact of wind speed and turbulence intensity on the flicker emission when operating at leading and lagging power factors. Flicker levels at the PCC of the wind farm are exacerbated with the increase of turbulence intensity independent of operating power factor. Similarly the flicker emission from the wind farm aggravates with increasing wind speed up to a certain wind speed value and then reduces as shown in [6], irrespective of operating power factor.

\section{Flicker Propagation in the Distribution NETWORK WITH WIND GENERATION}

Flicker caused by the variable active and reactive power output from the wind farm will propagate to different parts of the network with some attenuation. However, propagation depends on the operating power factor of the wind farm as illustrated in Fig. 6-(a). Fig 6-(b) depicts the change of $\mathrm{P}_{\mathrm{st}}$ as a function of the short-circuit capacity at each busbar.

With reference to Fig. 6-(b) flicker propagated from the wind farm diminish with the increase of short-circuit capacity along the feeder, when the wind farm is operating in leading power factor. For example th e short-term flicker severity of 0.3640 at the PCC of the wind farm (corresponds to short-circuit level of $97 \mathrm{MVA}$ ) has been reduced to 0.1266 at the MV busbar (corresponds to short-circuit level of 191 MVA), under 0.95 leading power factor operation. Similar observation can be made with reference to the unity power factor. However it is observed that flicker level recede at the T_T1 terminal compared to the MV busbar under unity power factor operation. This is because there is a small amount of reactive power injection/absorption from the wind farm even at unity power factor operation. This is due to the fact that the controller of the DFIG is not fast enough to respond to the active power change. In contrast, the flicker levels have remained approximately constant irrespective of the shortcircuit capacity when operating with lagging power factor, as the flow of active and reactive power are in two different direction. Furthermore, flicker level at the MV busbar has aggravated under lagging power factor compared to the same leading power factor. The effective impedance at the MV busbar is mainly reactive, therefore, only the reactive power change will lead to the voltage change at the MV busbar. Therefore, the relative voltage change ( i.e. $\Delta V / V$, where $V$ is the voltage at the MV busbar) is greater when the wind 
farm is absorbing reactive power (due to $V$ being lower when the reactive power is absorbing compared to reactive power is injecting). Accordingly, $\mathrm{P}_{\text {st }}$ will be higher under lagging power factor operation. In addition, flicker propagation from distribution network to the HV network is substantially less irrespective of the operating power factor of the wind farm as seen in Fig. 6-(b).

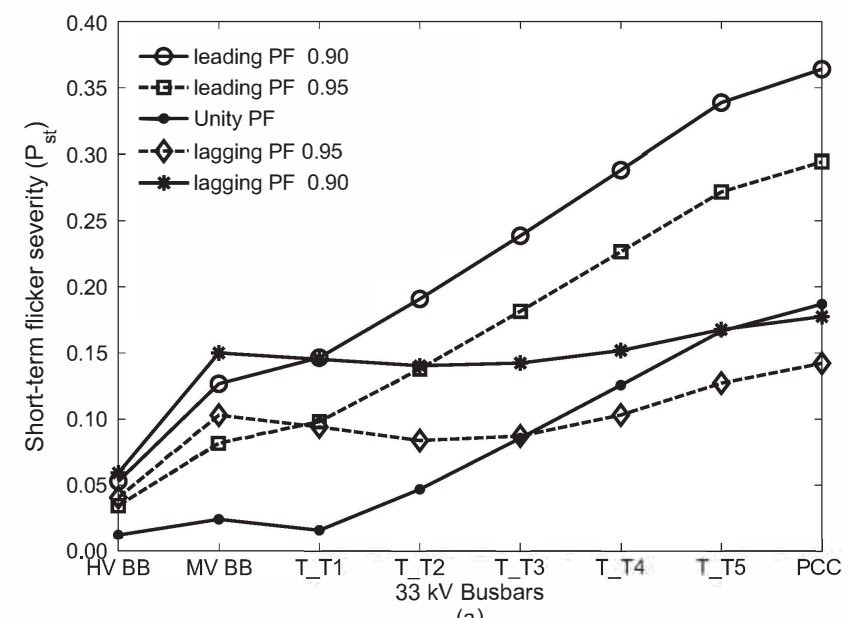

(a)

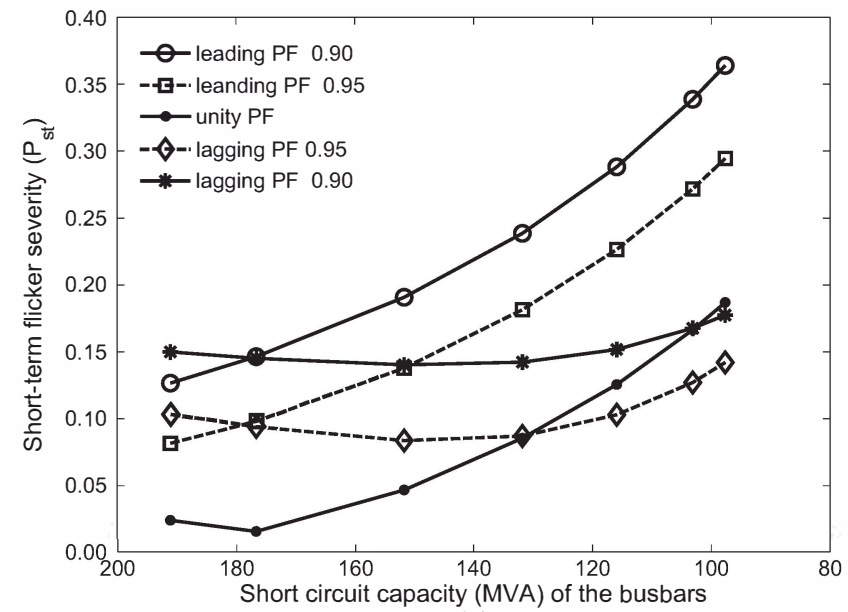

(b)

Fig. 6. (a) Short-term flicker severity in each busbar under different power factor operations; (b) Short-term flicker severity as a function of short-circuit capacity of each busbar

\section{CAse Study}

Section II demonstrate that the $\mathrm{Z}, \mathrm{I}$ and $\mathrm{P}$ loads respond distinctively when connected to a electrical network with a flicker source. Therefore, the impact of such loads when they are connected to a distribution network with a wind farm need to be investigated. A schematic of the network discussed in Section III with loads connected to terminal T_T1 to T_T5 is given in Fig. 7. The wind farm is operating with leading power factor of 0.95 in order to maintain the voltage along the feeder within acceptable levels [21]. Short-term flicker severity at each busbar is obtained when: (a) no loads are connected, (b) constant impedance loads, (c) constant current loads, (d) constant power loads, (e) ZIP loads ( $\mathrm{Z}=33.33 \%$, I =33.33\%, $\mathrm{P}=33.33 \%)$, each with capacity of $3.3 \mathrm{MW} / 0.9$ lagging

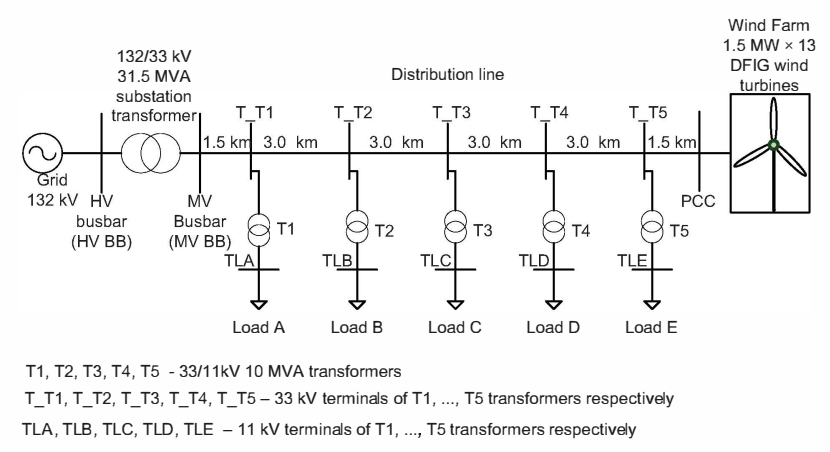

Fig. 7. Single line diagram of the $33 \mathrm{kV}$ distribution network with the wind farm and loads

power factor (f) induction motor with $3.3 \mathrm{MW} / 0.9$ power factor, are connected to terminal T_T1, to T_T5 through 33/11 $\mathrm{kV}$ transformers. In avarage the active power and reactive power from the wind farm is less than active and reactive power demand of the loads due to varaible wind genaration. Therefore, power deficit is provided by the grid, resulting a bi-directional active and reactive power flow in the distribution feeder. Fig. 8 provides a comparison of the $P_{\text {st }}$ values for all cases. Moreover, Fig. 8-(b) compares the $\mathrm{P}_{\text {st }}$ in the $11 \mathrm{kV}$ buses under previously discussed scenarios.

Fig. 8-(a) demonstrates that the flicker emission from the wind farm, and the flicker propagation to upstream network is well dependent on the load composition of the feeder. Flicker levels has exacerbated when loads are connected to the network, compared to the case where there are no loads connected. For instance, short-term flicker severity at terminal T_T3 has increased from 0.1815 to 0.2426 when constant impedance loads are present in the network. Moreover, the flicker levels are severe when constant power loads are connected to the network. In comparison with constant power loads, flicker has attenuated when induction motor loads are connected to the network as illustrated in [15]. The comparison of induction motor loads with constant impedance and constant current loads are not possible as the power drawn by each load is different. Furthermore, it can be observed that the behaviour of ZIP load resembles the behaviour of constant current load. This is due to, increase of voltage change $\left(\Delta V_{\text {load }}\right)$ by the constant power component of the load is canceled by the attenuation of voltage change by the constant impedance component of the load. Moreover, the flicker levels at the 11 $\mathrm{kV}$ terminals are also dependent on the load type connected to the distribution feeder as shown in Fig. 8-(b).

\section{CONCLUSION}

This paper investigates flicker propagation characteristics of a distribution feeder with wind generation. Initially flicker propagation characteristics were analysed for different load types using a standard flicker source connected to a distribution feeder, and it has shown that constant power and current loads exacerbate the flicker levels at the load terminal. Furthermore, this study has shown that flicker emission and flicker propagation along a distribution feeder depends on 


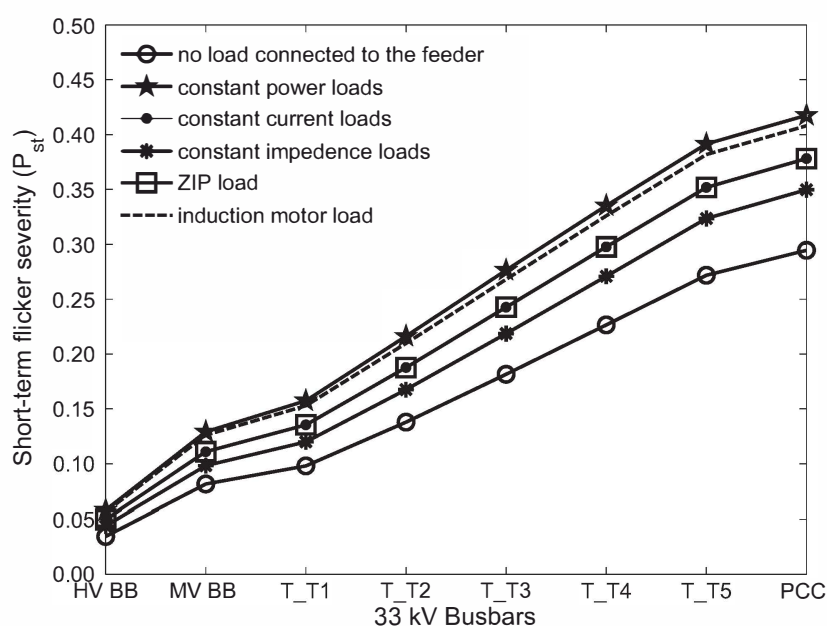

(a)

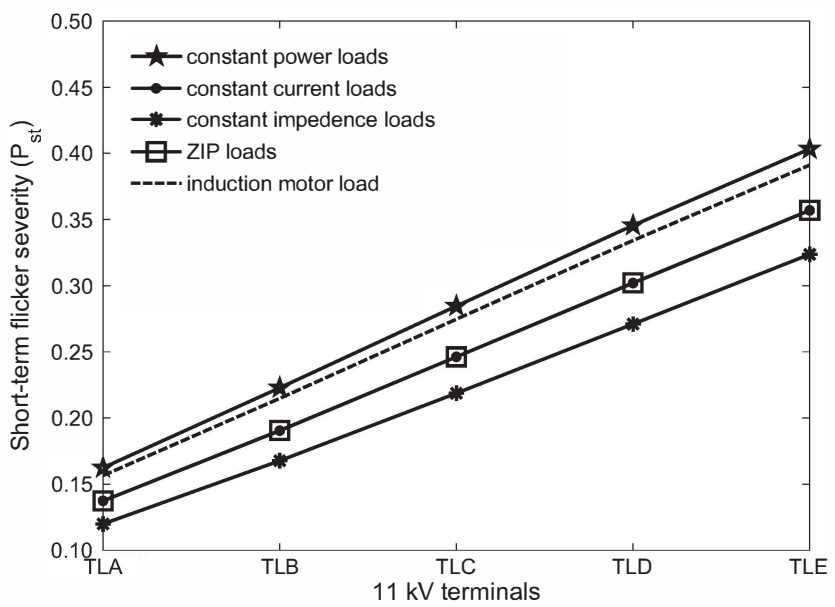

(b)

Fig. 8. (a) Short-term flicker severity values in each $33 \mathrm{kV}$ busbar under different loading configurations; (b) Short-term flicker severity values in each $11 \mathrm{kV}$ busbar under different loading configurations

operating power factor of the wind farm and the impedance of the feeder. A case study was developed using a distribution feeder consisted of a wind farm and investigated the flicker propagation along the distribution feeder with different load types and has illustrated the influence of the load types on flicker propagation. The outcome of the study is beneficial for improving the existing flicker emission standards in wind generation. Future studies will investigate flicker propagation with different control strategies and capability characteristics for wind generators. A mathematical model will also be developed in order to characterise the flicker propagation and attenuation with bidirectional power flows in distribution feeders.

\section{REFERENCES}

[1] Global Wind Energy Council, "Global wind report: annual market update 2011,” [Online], Available:www.gwec.net.

[2] "Wind energy- the facts part II grid interactions" [Online], Available: http://www.wind-energy-thefacts.org/documents/download/Chapter2.pdf.

[3] B. Fox, D. Flynn, L Bryans, N. Jenkins, D. Milborrow, M. O'Malley, $\mathrm{R}$. Watson and O. Anaya-Lara, "Wind power integration: connection and system operational aspects," First Ed., IET Power and Engineering Series 50, 2007.
[4] M.P. Papadopoulos, S.A. Papathanassiou, S.T. Tentzerakis and N.G. Boulaxis, "Investigation of the flicker emission by grid connected wind turbines," in Proc. 8th Int. Conf. Harmonics and Quality of Power, Athens, Greece, Oct. 1998, vol.2, pp.1152-1157.

[5] A. Larsson, "Flicker emission of wind turbines during continuous operation," Power Engineering Review, IEEE , vol.22, no.2, pp.59, Feb. 2002.

[6] T Sun, Z. Chen and F. Blaabjerg, "Flicker study on variable speed wind turbines with doubly fed induction generators," IEEE Trans. Energy Convers., vol.20, no.4, pp. 896- 905, Dec. 2005.

[7] C. Vilar Moreno, D. Amaris Duarte and J. Usaola Garcia, "Propagation of flicker in electric power networks due to wind energy conversions systems," IEEE Trans. Energy Convers., vol.17, no.2, pp.267-272, Jun 2002.

[8] C. Kocatepe, A. Inan, O. Arikan, R. Yumurtaci, B. Kekezoglu, M. Baysal, A. Bozkurt and Y. Akkaya, "Power quality assessment of gridconnected wind farms considering regulations in Turkey," Renewable and Sustainable Energy Reviews, vol. 13, no. 9, pp. 2553-2561, Dec. 2009.

[9] L. Meegahapola, and S. Perera, "Impact of wind generator control strategies on flicker emission in distribution networks," in 15th Int. Conf. Harmonics and Quality of Power, , Hong-Kong, Jun. 2012 [Accepted].

[10] R. Piwko, P. Meibom,H. Holttinen, S Baozhuang, N. Miller, C. Yongning and W. Weisheng, "Penetrating insights: lessons learned from large-scale wind power integration," IEEE Power and Energy Magazine, vol.10, no.2, pp.44-52, March 2012.

[11] M.C. Simoes and S.M. Deckmann, "Flicker propagation and attenuation," in Proc. 10th Int. Conf. Harmonics and Quality of Power, vol.2, pp. 644- 648, Oct. 2002.

[12] E. De Jaeger, G. Borloo and W. Vanceotsem, "Fliker transfer coefficient from HV to MV and LV systems," in Proc. 14th Int. Conf. Electricity Distribution, (CIRED97), Birmingham, U.K., pp101-102, June 97, pp. 101-102.

[13] S. Perera, D. Robinson, S. Elphick, D. Geddey, N. Browne, V. Smith and V. Gosbell, "Synchronized flicker measurement for flicker transfer evaluation in power systems," IEEE Trans. Power Del, vol.21, no.3, pp.1477-1482, July 2006.

[14] "Review of flicker objectives for LV, MV and HV sytems," CIGRECIRED Working Group C4.108, Tech. Rep. V1.1, Feb. 2011.

[15] S . Tennakoon, S. Perera and D. Robinson, "Flicker attenuation part I: response of three-phase induction motors to regular voltage fluctuations," IEEE Trans. Power Del, vol.23, no.2, pp.1207-1214, April 2008.

[16] S . Tennakoon, S. Perera and D. Robinson, "Flicker attenuation part II: transfer coefficients for regular voltage fluctuations in radial power systems with induction motor loads," IEEE Trans. Power Del, vol.23, no.2, pp.1215-1221, April 2008

[17] L. Meegahapola, B. Fox and D. Flynn, "Flicker mitigation strategy for DFIGs during variable wind conditions," in Proc. IEEE PES GM 2010, IEEE, pp.1-8, 25-29 July 2010.

[18] A.D. Hansen, F. Iov, P.E. Srensen, N.A. Cutululis, C. Jauch, and F. Blaabjerg, "Dynamic wind turbine models in power system simulation tool DIgSILENT," Ris report Ris-R-1400(EN), Denmark, 2007.

[19] J.V. Seguro and T.W. Lambert, Modern estimation of the parameters of the Weibull wind speed distribution for wind energy analysis, Journal of Wind Engineering and Industrial Aerodynamics, vol. 85, no. 1, pp. 75-84, Mar. 2000

[20] DIgSILENT GmbH, "DIgSILENT PowerFactory Version 14.1 User's Manual Volume II," May 2011

[21] "Standard Voltages", AS 60038, Standards Australia, 2000 